\title{
Understanding the Crystallinity Indices Behavior of Burned Bones and Teeth by ATR-IR and XRD in the Presence of Bioapatite Mixed with Other Phosphate and Carbonate Phases
}

\author{
Giampaolo Piga, ${ }^{1}$ David Gonçalves, ${ }^{2,3,4}$ T. J. U. Thompson, ${ }^{5}$ Antonio Brunetti, ${ }^{1}$ \\ Assumpció Malgosa, ${ }^{6}$ and Stefano Enzo ${ }^{7}$ \\ ${ }^{1}$ Department of Political Science, Communication, Engineering and Information Technologies, University of Sassari, \\ Viale Mancini 5, 07100 Sassari, Italy \\ ${ }^{2}$ Research Centre for Anthropology and Health (CIAS) and Department of Life Sciences, Universidade de Coimbra, \\ Calçada Martim Freitas, 3000-456 Coimbra, Portugal \\ ${ }^{3}$ Laboratory of Forensic Anthropology, Department of Life Sciences, Faculdade de Ciências e Tecnologia, Universidade de Coimbra, \\ Calçada Martim Freitas, 3000-456 Coimbra, Portugal \\ ${ }^{4}$ Laboratório de Arqueocièncias, Direcção General do Património Cultural and LARC/CIBIO/InBIO, Rua da Bica do Marquês 2, \\ 1300-087 Lisbon, Portugal \\ ${ }^{5}$ School of Science \& Engineering, Teesside University, Borough Road, Middlesbrough TS1 3BA, UK \\ ${ }^{6}$ Unitat d’Antropologia Biologica, Department de Biologia Animal, Biologia Vegetal i Ecologia, Universitat Autonoma de Barcelona, \\ Edifici C, Bellaterra, 08193 Barcelona, Spain \\ ${ }^{7}$ Department of Chemistry and Pharmacy, University of Sassari, Via Vienna 2, 07100 Sassari, Italy
}

Correspondence should be addressed to Giampaolo Piga; giapiga@uniss.it

Received 4 November 2015; Accepted 3 January 2016

Academic Editor: Jozef Kaiser

Copyright (c) 2016 Giampaolo Piga et al. This is an open access article distributed under the Creative Commons Attribution License, which permits unrestricted use, distribution, and reproduction in any medium, provided the original work is properly cited.

\begin{abstract}
We have critically investigated the ATR-IR spectroscopy data behavior of burned human teeth as opposed to the generally observed behavior in human bones that were subjected to heat treatment, whether deliberate or accidental. It is shown that the deterioration of the crystallinity index (CI) behavior sometimes observed in bones subjected to high temperature appears to be of higher frequency in the case of bioapatite from teeth. This occurs because the formation of the $\beta$-tricalcium phosphate $(\beta$-TCP) phase, otherwise known as whitlockite, clearly ascertained by the X-ray diffraction (XRD) patterns collected on the same powdered specimens investigated by ATR-IR. These results point to the need of combining more than one physicochemical technique even if apparently well suitable, in order to verify whether the assumed conditions assessed by spectroscopy are fully maintained in the specimens after temperature and/or mechanical processing.
\end{abstract}

\section{Introduction}

The study of burned human remains is of considerable importance in archaeology, forensic anthropology, and crime scene investigations. We can have the presence of fire in many situations such as accidents and homicides. In fact fire is a common method for attempting to conceal evidence of criminal activity inflicted on human victims.

To know the temperatures at which a bone was subjected is a great index to better understand the modifications suffered by bone structures due to combustion [1] to promote the differentiation between natural and anthropogenic phenomena and to better interpret the techniques used in the resolution of forensic cases where cremation or other fire damage to remains is present [2-6].

At this microscopic scale, there are two key features influenced by heating that are worth exploring: changes to the elemental composition and changes to the crystalline structure of the bone. 
Thus, new and accurate experimental methods are needed to clarify the variety of factors that lead to varying levels of thermal effects.

It has been argued that the most appropriate means of addressing microstructural studies of burned bones are the physicochemical and spectroscopic approaches, such as the Fourier Transform Infrared Spectroscopy (FT-IR) and X-ray diffraction (XRD) [7-14]. In recent years, many researchers have turned their attention to alternative ways of studying and identifying burned bones. For this purpose, the potential of the crystallinity index (CI) - or splitting factor (SF) has been investigated intensively [9, 15-22], although the applications on real forensic or archaeological scenarios are still rare in literature [20-23]. CI can be measured with both X-ray diffraction (XRD) and Fourier Transform Infrared Spectroscopy (FT-IR). Although both methods have been used in the literature $[20,21,23]$, the CI values defined using XRD cannot be directly compared to those created using FTIR $[11,18,24]$.

$\mathrm{XRD}$ is ideal for defining a crystallinity parameter of the bioinorganic phase as the pattern involves directly the effect of 3D periodicity (i.e., the organization degree in all directions) of the elementary cell, the smallest unit fundamental for expressing the physical, chemical, and symmetry properties of a crystal. Conversely, the FT-IR spectroscopy supplies a fingerprint of the chemical environment surrounding the bond vibrations excited by the frequencies of the IR incoming beam. Nevertheless, it should be maintained that FT-IR is advantageous to define a fresh bone because it is particularly sensible to the presence of genetic matter as it can be verified in the frequency range $1300-1700 \mathrm{~cm}^{-1}$ [25]. On the contrary, hard X-ray radiation used in diffraction is relatively insensitive to the presence of such component.

FT-IR spectroscopy has the potential for being portable into the field, requires a very small amount of sample, can be cheaper to use, and has been shown to be more accurate at lower burning temperatures [16, 26, 27]. In particular, the methodology of KBr FT-IR, for the sample preparation, involves laborious dilution in a transparent means while with FT-IR ATR (attenuated total reflectance) the infrared beam impinges directly a large area of the sample [18], maximizing the reproducibility of the signals regardless the protocols followed by the operator.

However, the accuracy of temperature determination solely using the FT-IR approach has some critical aspects. In the absence of long range order information, it is generally assumed that the inorganic apatite component remains as a single phase, but this may not always be the case once the bone is subjected to a high-temperature treatment. In fact when bioapatite is subjected to a thermal treatment, we can find also a multiphase condition for the resultant product due to a transformation of a part of hydroxylapatite (HA) to the $\beta$ three-calcium-phosphate phase ( $\beta$-TCP) of a mineral named whitlockite [28].

The presence of $\beta$-TCP as well as the presence of other mineralogical phases due to various taphonomy effects can strongly alter the shape of $v_{4}-v_{3}$ bands; consequently, the calculation of the CI and all the recently proposed ratios by Thompson et al. [29] may not be correct. That is why a multidisciplinary approach would be always advisable, possibly with the combined use of various physicochemical techniques such as ATR-IR and XRD.

In this sense, we present in this paper a collection of comparative examples using animal and human bones combined with synthetic apatite heat-treated at selected temperatures. The trend of CI was inspected in order to identify advantages and limitations of the use of the FT-IR spectroscopic technique in the study of burned bones.

\section{Material and Methods}

The human bones fragments and teeth employed in this study were kindly made available from the Universitat Autonoma de Barcelona (Spain). The cremated human teeth originate from the Necropolis of Monte Sirai (Carbonia, Italy). The pig bone specimens were kindly made available from the Department of Animal Biology, University of Sassari (Italy). Synthetic powder hydroxylapatite was synthesized by Aldrich Chemistry ${ }^{\circledR}$.

The samples were heat-treated in air using a NEY muffle furnace at selected temperatures $\left(500-700-900-1100^{\circ} \mathrm{C}\right.$ for 10 and 40 minutes), using a rate of $20^{\circ} \mathrm{C} / \mathrm{min}$ both for heating and for cooling the bone specimens.

FT-IR spectra were collected in ATR mode with a Bruker Alpha Platinum-ATR interferometer in terms of absorbance versus wavenumber $v$ in the range $370-4000 \mathrm{~cm}^{-1}$, with a resolution of $4 \mathrm{~cm}^{-1}$. Each spectrum was obtained by averaging 256 interferograms. The loose powder was dispersed inside a hole cavity of spheroidal shape with its surface aligned to the plate defining it.

The crystallinity index adopted here is the same as that used in the majority of archaeological and forensic applications. The absorption bands at 605 and $565 \mathrm{~cm}^{-1}$ were used following baseline correction, and the heights of these absorptions peaks were summed and then divided by the height of the minimum between them [30].

The bone samples were analyzed with a Bruker M4 Tornado $\mu$-XRF spectrometer using a Rh X-ray source model MCBM 50-0.6 B working at $50 \mathrm{kV}$ and $600 \mu \mathrm{A}$ under vacuum (20 mbar) and using an Al filter $12.5 \mu \mathrm{m}$ thick. In order to check the macroscopic chemical homogeneity, a series of 20 spectra were collected for each bone specimen. Each spectrum was accumulated for $600 \mathrm{~s}$.

The XRD patterns were collected using Bruker D2 Phaser instrument working at a power of $30 \mathrm{kV}$ and $10 \mathrm{~mA}$ in the Bragg-Brentano vertical alignment with a $\mathrm{Cu}-\mathrm{Ka}$ tube emis$\operatorname{sion}(\lambda=1.5418 \AA)$.

The width of divergent and antiscatter slits was $1 \mathrm{~mm}$ $\left(0.61^{\circ}\right)$; primary and secondary axial Soller slits of $2.5^{\circ}$ were also mounted with a linear detector LYNXEYE with $5^{\circ}$ opening and a monochromatisation by $\mathrm{Ni}$ foil for the $\mathrm{Kb}$ radiation. The powder patterns were collected in the angular range $9^{\circ}-140^{\circ}$ in $2 \theta$ with a step size of $0.05^{\circ}$. The collection time of each pattern was pursued for $47 \mathrm{~min}$. Our sample holder for XRD analysis is a circular cavity of $25 \mathrm{~mm}$ in 


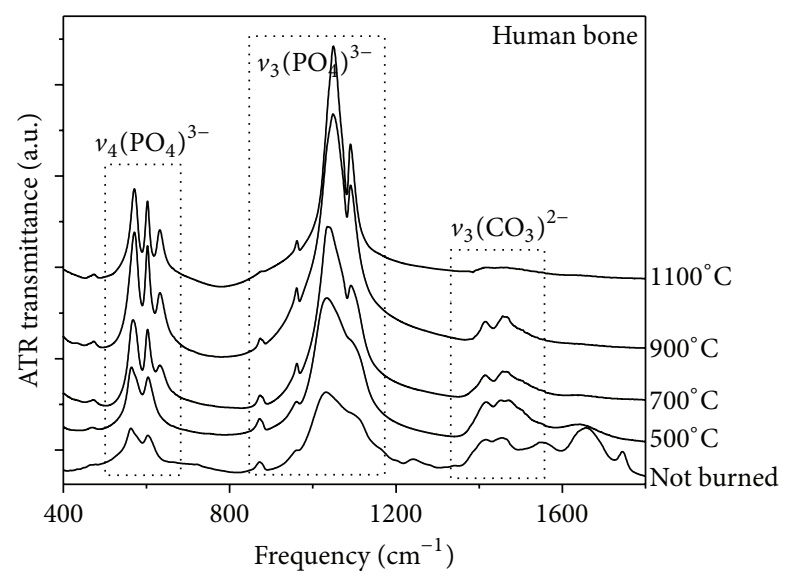

FIGURE 1: The ATR transmittance spectrum of a human unburned bone (bottom pattern) and that for the same specimen treated at the $500-1100^{\circ} \mathrm{C}$ temperature range. It is possible to appreciate a whole conventional evolution of bands as discussed in the text.

diameter and $2 \mathrm{~mm}$ in depth, containing about $190 \mathrm{mg}$ of powder bone.

Digitized diagrams were initially subjected to preprocessing for qualitative phase recognition according to the programs Highscore ${ }^{\circledR}$ and Match ${ }^{\circledR}$ and then analyzed quantitatively according to the Rietveld method [31], using the programme MAUD [32]. It is worth noting that one stringent requirement of any Rietveld program needs the correct loading of the crystal structure solution of substances not only concerning space group and lattice parameters but also including atomic location of the asymmetric unit [33].

\section{Results and Discussion}

In Figure 1, we report a conventional behavior of the FTIR spectra collected in ATR mode as a function of reported temperature values $\left(500,700,900\right.$, and $1100^{\circ} \mathrm{C}$, for 10 minutes) for a human bone.

Summarizing briefly, the $v_{4}\left(\mathrm{PO}_{4}\right)$ and $v_{3}\left(\mathrm{PO}_{4}\right)$ bands occur in the $500-700$ and $850-1200 \mathrm{~cm}^{-1}$ range, respectively. The series of bands in the range $1300-1800 \mathrm{~cm}^{-1}$, particularly those at 1417 and $1660 \mathrm{~cm}^{-1}$, are attributed to the presence of carbonate groups in bone material and to the organic genetic components, respectively, and can be used as a means for quantitative evaluation of their presence during drying $[18,34]$.

Our spectra evolution in such range confirms the usefulness and convenience of the proposed approach. We can also note increasing sharpening of the $v_{3}$ and $v_{4}$ bands attributed to phosphate groups. In particular, the $v_{4}$ bands are further used as a means to study the CI evolution through numerical evaluation of the splitting factor SF in the pertinent range selected as a function of temperature and reported in Figure 2.

On this clear evidence, the calibration of the $\mathrm{CI}$ as a function of temperature has been reversed in order to

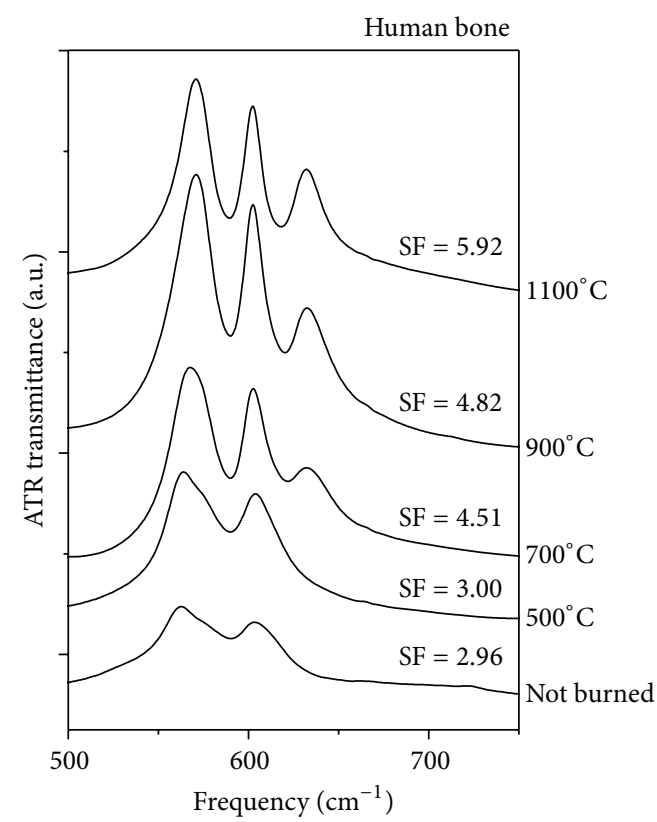

Figure 2: The $v_{4}\left(\mathrm{PO}_{4}\right)$ bands are also magnified in the frequency range where the $\mathrm{CI}$ crystallinity index or SF splitting factor are worked out numerically and their figures reported.

estimate the temperature to which a bone specimen was subjected after a fire event [18-20].

It is obvious that the reliability of such results depends on the validity of assumptions involved in the study underway and strictly maintained by the sample under investigation. In particular, the infrared spectroscopy is sensible to the vibrations modes around selected atomic species (or molecular groups) in a solid, crystalline matrix. It is expected that such matrix when subjected to thermal treatment enforces its crystalline properties, that is, its degree of (3D) spatial organization in the course of a thermal treatment. This may occur in at least two different but concomitant ways: (i) crystal growth and (ii) elimination of imperfections from the regular lattice. In both cases, it is implicitly assumed that the main parameters governing the crystal symmetry (i.e., the symmetry operation, i.e., the space group assumed by the crystal) are not changing. Whether this occurs or not can be inspected clearly by X-ray diffraction.

Figure 3 shows the behavior of the ATR-IR spectra of human teeth as a function of reported temperature values $\left(500,700,900\right.$, and $1100^{\circ} \mathrm{C}$, for 40 minutes). Tooth enamel is another bioapatite product whose crystallinity study versus temperature could be addressed by ATR similar to human bones. Making reference to the range $1300-1800 \mathrm{~cm}^{-1}$, we may note better the carbonate bands (and their progressive disappearance) rather than those of the genetic material, here less evident.

Of course these bands are disappearing in the hightemperature spectra. If we follow simultaneously the $v_{4}$ band evolution we may envisage a complex progression of signals (see Figure 4). 


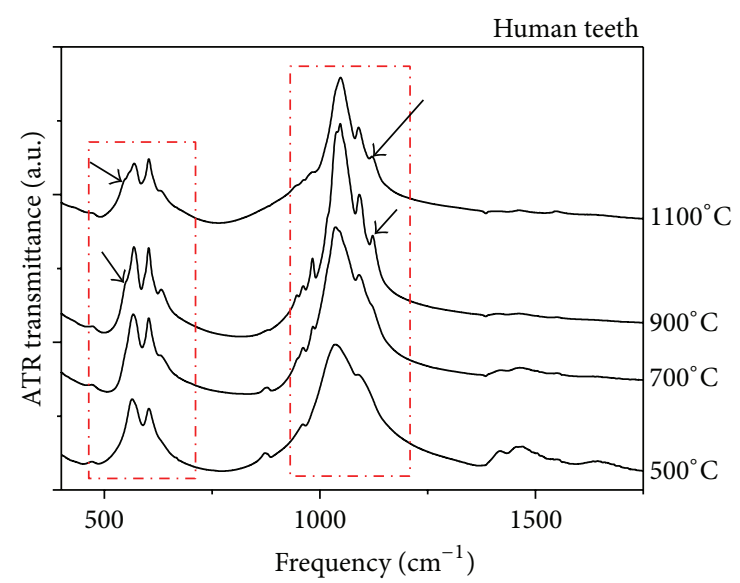

Figure 3: The spectra evolution as a function of temperature treatment for a human tooth shows an unconventional behavior for the $v_{4}\left(\mathrm{PO}_{4}\right)$ band in terms of crystallinity index values. We can also note an additional peak which appears at ca. $1123 \mathrm{~cm}^{-1}$ as indicated by arrows.

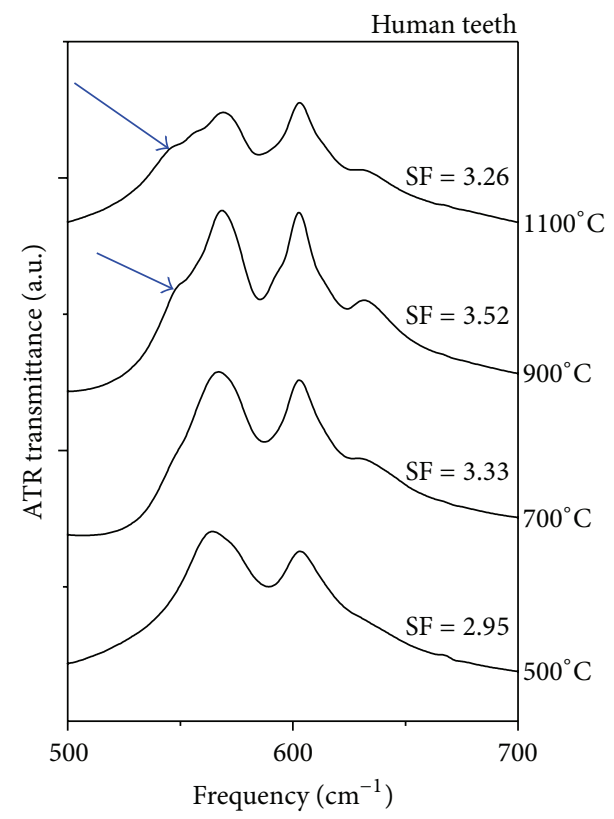

Figure 4: Magnification of the $v_{4}$ band evolution; we may envisage a complex progression of signals. In this case, the values of SF do not present an increasing monotonic trend with temperature but remain nearly constant around 3.3-3.4. Note the shoulder which appears at about $547 \mathrm{~cm}^{-1}$ attributable to $\beta$-TCP phase.

In this case the values of SF do not present an increasing monotonic trend with temperature but remain nearly constant around 3.3-3.4.

As a matter of fact, in the temperature range $700-1100^{\circ} \mathrm{C}$ from the XRD pattern we were able to recognize the presence of $\beta$-TCP phase. On account of the new system created, the IR bands of $\beta$-TCP are expected to overlap with the bands of bioapatite. An additional peak at ca. $1123 \mathrm{~cm}^{-1}$ (see Figure 3) and the shoulder which appears at about $547 \mathrm{~cm}^{-1}$

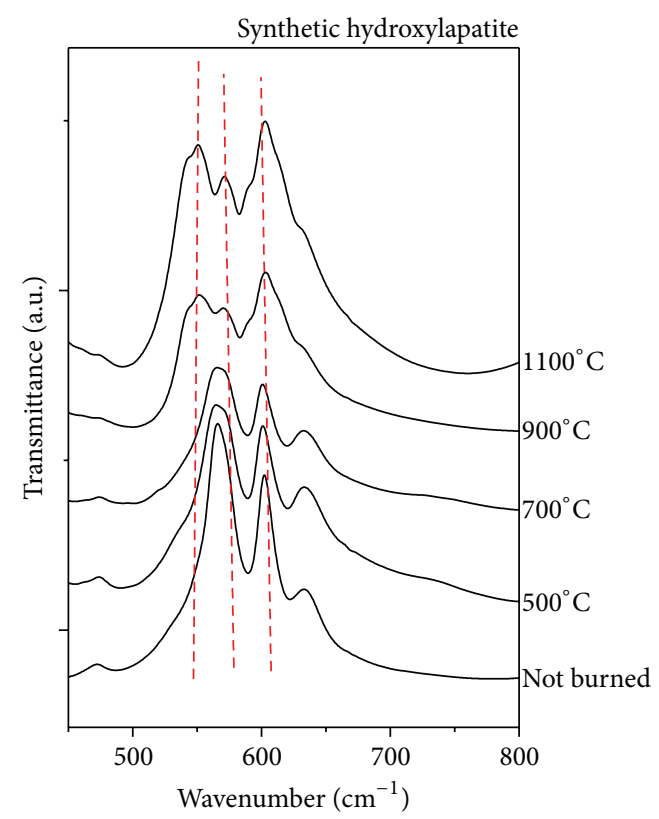

FIgURE 5: The ATR experiment involving synthetic hydroxylapatite displays the emergency of high-temperature features sensibly affecting the conventional band shape and sharpening, to the point of making any $\mathrm{CI}$ determination useless.

(see Figure 4) as indicated by arrows are attributable to $\beta$ TCP.

To this regard, Figure 5 shows ATR-IR curves in correspondence with the $v_{4}\left(\mathrm{PO}_{4}\right)$ band for the transformation behavior of synthetic hydroxylapatite as a function of the indicated temperatures. Although the curve of unburned synthetic hydroxylapatite shows features different from untreated bioapatite, we may notice that, from 700 up to $1100^{\circ} \mathrm{C}$, the high temperature bands with new components are heavily affected with respect to their original shape to the point of making any SF determination useless.

Figures 6,7 , and 8 refer to the changes of the $v_{4}$ band shape due to the presence of $\beta$-TCP at various levels in three different specimens, all of them subjected to high temperature heat treatment, supplemented with XRD patterns and corresponding Rietveld fit.

Figure 6(a) shows a conventional pattern of a cremated human tooth from an archaeological cremation. The burning temperature reached during the process is unknown. Nevertheless, the value of SF (5.68) permits estimating roughly the temperature [18-20]. Note that the peak at $562 \mathrm{~cm}^{-1}$ is of intensity higher than that of the peak at $600 \mathrm{~cm}^{-1}$. The XRD phase analysis of Figure 6(b) shows that in addition to the predominating presence of bioapatite (red curve) there is a weak appearance $(11 \%$ wt.) of the $\beta$-TCP phase (blue curve). Accordingly, the bar sequences at the bottom mark the expected position of peaks for the indicated phases. The curve below represents the residuals, that is, the difference between the square root of calculated and experimental intensities, respectively.

Figure 7(a) shows a pig bone which was treated at $1100^{\circ} \mathrm{C}$ in a muffle furnace for 10 minutes. With respect 


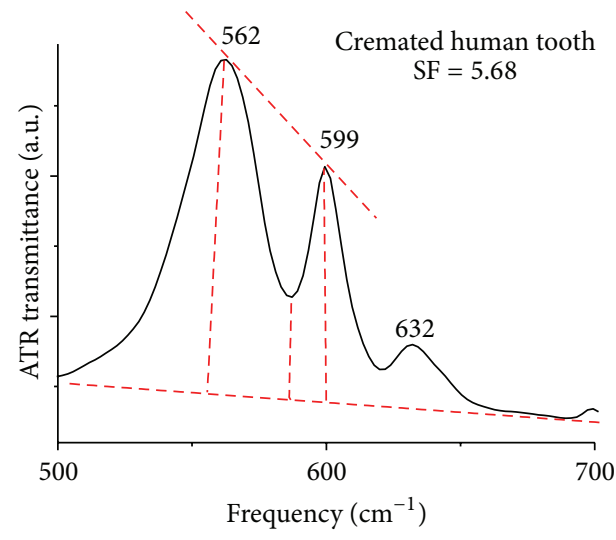

(a)

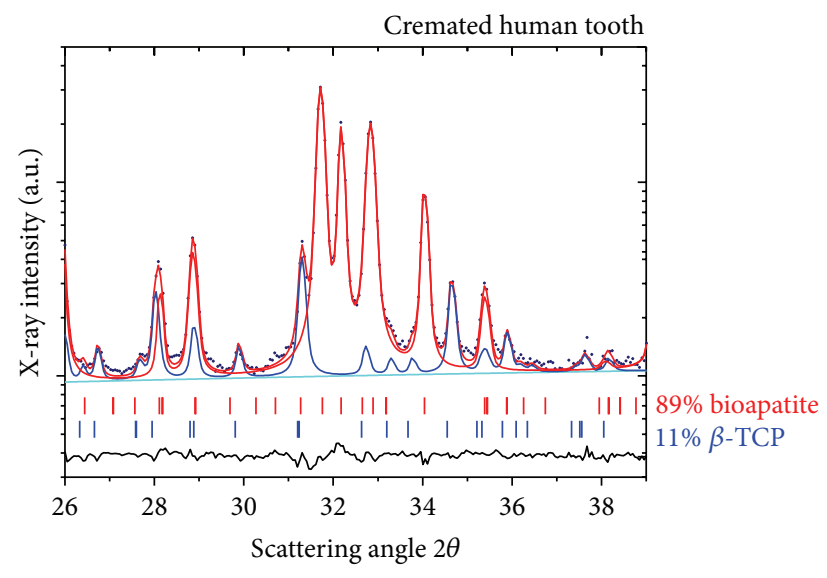

(b)

FIgURE 6: A detailed comparison of different FT-IR curves collected for three different bioapatite specimens with the correspondent XRD patterns and relevant Rietveld phase evaluation. The distortions of ATR curves with respect to the conventional expected behavior are strictly related to the amount of $\beta$-TCP phase which was stimulated by the high-temperature treatment as it clearly emerges from XRD analyses.

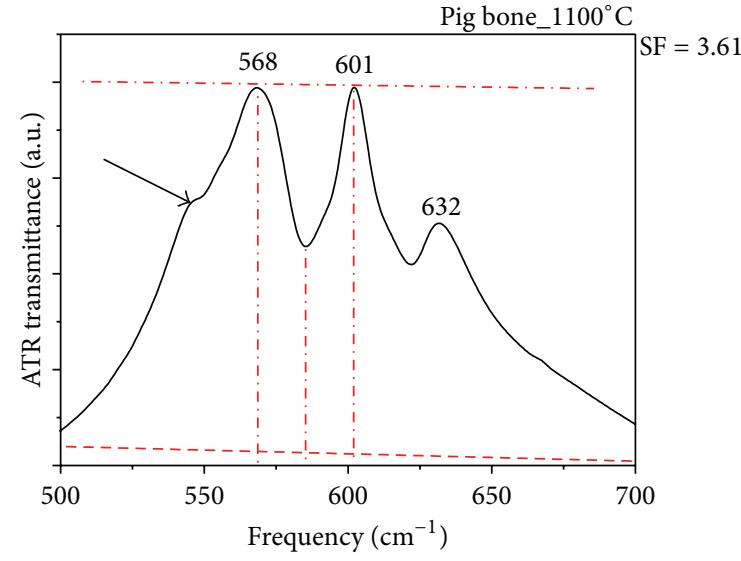

(a)

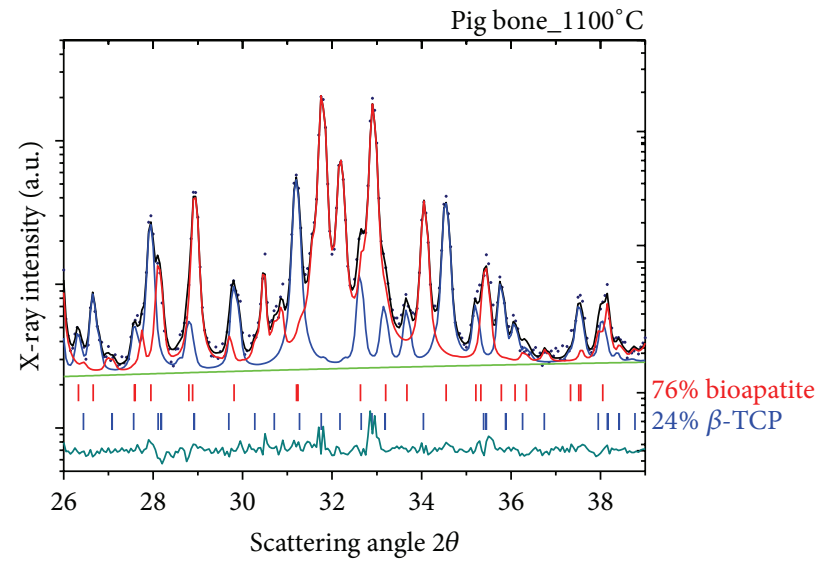

(b)

FIgURE 7: A detailed comparison of different FT-IR curves collected for three different bioapatite specimens with the correspondent XRD patterns and relevant Rietveld phase evaluation. The distortions of ATR curves with respect to the conventional expected behavior are strictly related to the amount of $\beta$-TCP phase which was stimulated by the high-temperature treatment as it clearly emerges from XRD analyses.

to the previous case, we may notice a substantial change of the band shape. In addition, the peaks at $568 \mathrm{~cm}^{-1}$ and $601 \mathrm{~cm}^{-1}$, respectively, show approximately the same height. Also note that the prominent shoulder previously indicated by the arrow in Figure 4 here is missing. According to the Rietveld fit of the XRD pattern (data points), this specimen had developed $24 \%$ of $\beta$-TCP and $86 \%$ of bioapatite (see Figure 7(b)).

Figure 8(a) represents an extreme case, in which a human tooth was treated in a furnace at $1100^{\circ} \mathrm{C}$ for 40 minutes. In this case, the relative intensities of the peaks at 569 and $603 \mathrm{~cm}^{-1}$, respectively, are reversed with respect to the curve recorded for the specimen shown in Figure 6(a).

Analysis of the correspondent XRD pattern has established the presence of $70 \% \beta$-TCP phase for such specimen (see Figure 8(b)). Refined lattice parameters turned out to be 10.37 and $37.23 \AA$ to compare with the values of $a=10.42$ and $37.42 \AA$, respectively, for pure commercial $\beta$ TCP (synthesized by Aldrich Chemistry ${ }^{\circledR}$ ).

The appearance of $\beta$-TCP from human bones seems difficult to account for [35] and has been related to the environmental $\mathrm{pH}$ and/or to presence of magnesium ions which may substitute for calcium. The transformation process involves multiple intermediates, the stability of which depends on the cation ( $\mathrm{Ca}$ and $\mathrm{Mg}$ ) activities and the solution $\mathrm{pH}$. However, in our studies of biomaterials such as bones and teeth, we never observed the $\beta$-TCP phase nor the clear presence of magnesium ions from XRF spectroscopy.

As is shown in Figure 9, the X-ray fluorescence spectra did not show evaluable peaks attributed to magnesium $(1.25 \mathrm{keV})$ for a list of specimens where high-temperature formation of $\beta$-TCP was reported. As is also seen in Figure 6, 


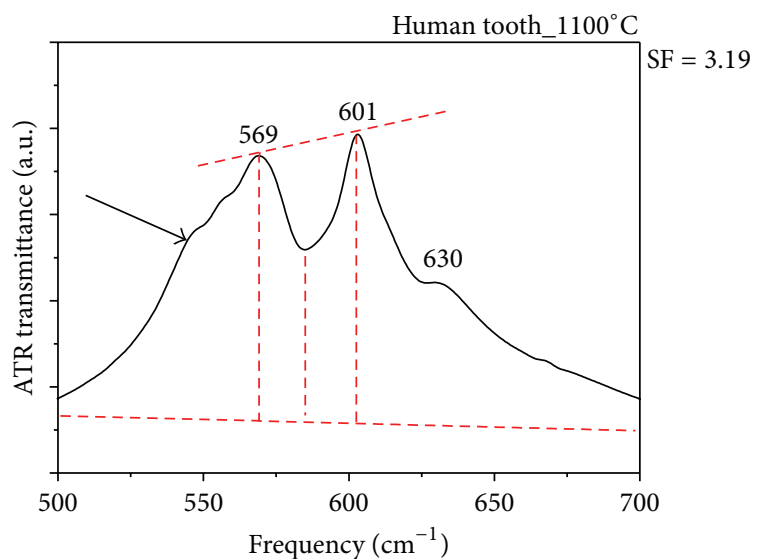

(a)

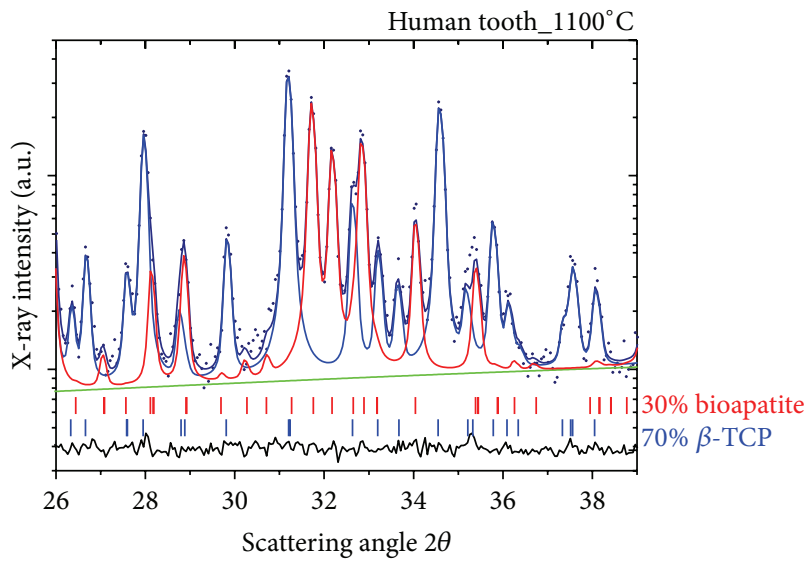

(b)

FIGURE 8: A detailed comparison of different FT-IR curves collected for three different bioapatite specimens with the correspondent XRD patterns and relevant Rietveld phase evaluation. The distortions of ATR curves with respect to the conventional expected behavior are strictly related to the amount of $\beta$-TCP phase which was stimulated by the high-temperature treatment as it clearly emerges from XRD analyses.

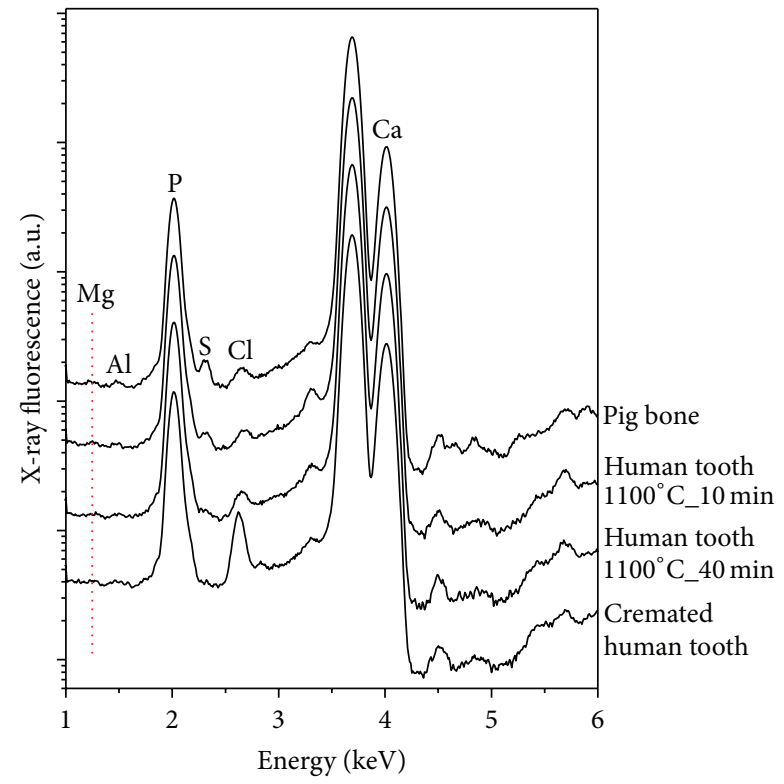

FIGURE 9: The XRF spectra analysis for bones and tooth where we have observed formation of $\beta$-TCP after a high temperature treatment. The peak of magnesium expected at $1.25 \mathrm{keV}$ appears to be totally absent for all spectra. This cast some doubts about the presumed role of $\mathrm{Mg}$ ions in stabilizing the $\beta$-TCP phase. Nevertheless there are other weak peaks from other elements ( $\mathrm{Al}$, $\mathrm{S}$, and $\mathrm{Cl}$ ) whose role should be inspected.

there are other chemical elements such as chlorine, sulphur, and perhaps aluminium that may be related with the observed transformation. A high-temperature treatment seems to be the necessary requisite in order to observe conversion of bioapatite to $\beta$-TCP [28].

In fact, Elliott [36] has suggested for bioapatite a general chemical equation of the type $\mathrm{A}_{5}\left(\mathrm{BO}_{4}\right)_{3}(\mathrm{X})$, where $\mathrm{A}=\mathrm{Ca}^{2+}$ or $\mathrm{Mg}^{2+}$ ions, $\mathrm{B}=\mathrm{P}$ or $\mathrm{S}$, and $\mathrm{X}=\mathrm{F}^{-}, \mathrm{OH}^{-}$, or $(1 / 2) \mathrm{CO}_{3}{ }^{2-}$.
When $\mathrm{A}=\mathrm{Ca}^{2+}, \mathrm{B}=\mathrm{P}(\mathrm{V})$, and $\mathrm{X}=\mathrm{OH}^{-}$, we meet the chemical equation of synthetic apatite transforming to pure $\beta$-TCP:

$$
2 \mathrm{Ca}_{5}\left(\mathrm{PO}_{4}\right)_{3} \mathrm{OH} \longrightarrow 3 \mathrm{Ca}_{3}\left(\mathrm{PO}_{4}\right)_{2}+\mathrm{CaO}+\mathrm{H}_{2} \mathrm{O}
$$

Of course in such high temperature reaction, gaseous water is supposed to be evolved, which may account for sporadic observations of teeth eruption and explosion during heattreatment, while solid $\mathrm{CaO}$ can rehydrate to $\mathrm{Ca}(\mathrm{OH})_{2}$ (portlandite) after cooling down at room temperature.

Unfortunately, there is no well-defined temperature for the above transformation reaction to occur, the main reasons being that, apart from $\mathrm{pH}$, bioapatite may be stabilized unpredictably also by grain boundaries, defects, and inclusion of various chemical species difficult to identify and evaluate properly.

The appearance of $\beta$-TCP phase from bones appears to be sporadic and seems to occur at temperatures around $1100^{\circ} \mathrm{C}$ [28]. Conversely for teeth, we have observed a more systematic occurrence of $\beta$-TCP at temperatures as low as $750^{\circ} \mathrm{C}$.

Figure 10 shows the sequence of Rietveld fit for the human teeth which were thermally treated in a furnace at 700,750 , 900 , and $1100^{\circ} \mathrm{C}$ for 10 minutes at a rate of $20^{\circ} \mathrm{C} / \mathrm{min}$ and then cooling in air. The patterns show the appearance of the $\beta$ TCP phase (blue full line) occurring at a temperature as low as $750^{\circ} \mathrm{C}$ and following peak sharpening.

A $\beta$-TCP amount of ca $5 \%$ from an otherwise bioapatite matrix can be ascertained from the XRD patterns in the $2 \theta$ range $26-37$ using our experimental conditions paying attention to its most intense peak $(0,2,10)$ occurring at $2 \theta$ $=31.18^{\circ}$ in reason of their lattice parameters $a=10.37$ and $c=$ $37.21 \AA$, respectively.

As can be seen in Figure 7, such shoulder emerges more clearly with other diagnostic peaks of $\beta$-TCP at higher temperatures of treatment, because of sharpening of the peaks related to the increase of the average crystallite size for 


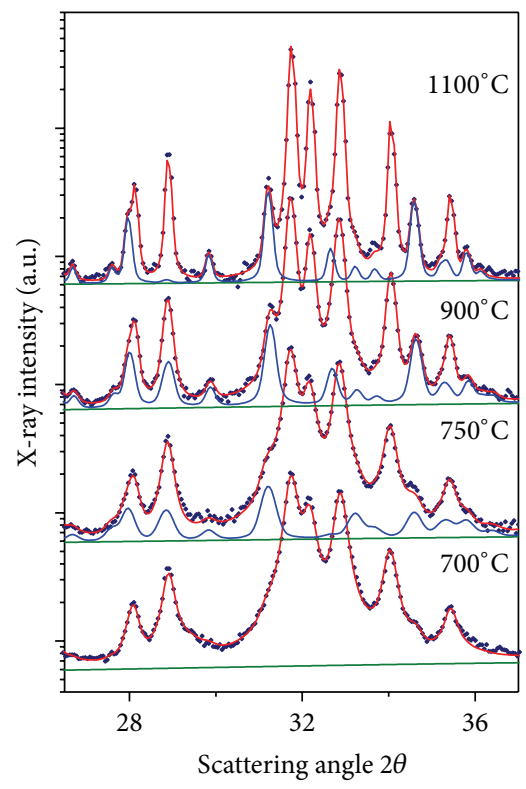

FIGURE 10: The series of XRD patterns for a tooth heat-treated at $700-1100^{\circ} \mathrm{C}$ temperature range suggest that the occurrence of $\beta$-TCP is observable by heating the specimen in a furnace as low as $750^{\circ} \mathrm{C}$ for 10 minutes at a rate of $20^{\circ} \mathrm{C} / \mathrm{min}$ and then cooling in air.

both bioapatite and $\beta$-TCP phases and/or release of internal strain.

Two other points are worth noting from Rietveld analysis:

(i) The amount of $\beta$-TCP separated at temperatures as high as $1100^{\circ} \mathrm{C}$ remains approximately around $14 \%$.

(ii) The lattice parameters of $\beta$-TCP remain essentially unchanged during the thermal process and the values are slightly below those determined in the literature of the "supposed magnesium stabilized" phase. Comparison with the XRD quantitative data reported in Figure 6(b) suggest that the holding time at a final temperature may help the kinetics of decomposition, at parity of temperature rate increase selected. Finally, we would like to add that the unknown phase reported from thermal treatments of dental tissue and synthetic hydroxylapatite in the synchrotron radiation patterns of Sui et al. [37] ( $\lambda$ is not reported but calculable as ca. $0.69 \AA$ ) is very likely the $\beta$-TCP phase.

We should note that such presence of $\beta$-TCP is hardly distinct in the $v_{4}$ band of phosphates in the ATR-IR spectrum because of their relative importance in comparison to bioapatite. Nevertheless, the $\mathrm{P}-\mathrm{O}$ bond length distribution of phosphate in bioapatite [38] is certainly different from phosphate bond length distribution in $\beta$-TCP [39].

\section{Conclusions}

The use of ATR-IR spectroscopy in the study of burned bones using the $v_{4}$ band of phosphates in the range $500-700 \mathrm{~cm}^{-1}$ may deserve special care in the case of occurrence of $\beta$-TCP (or equivalently other phosphate phases that in principle can react after chemical or physical treatments applied to the bioapatite). This is because the range of frequencies where the CI of bioapatite is determined turns out to be heavily affected by other bands of similar phosphate groups like those allocated in the $\beta$-TCP crystal structure. This emphasize the use of XRD as a valuable tool for supplementing the studies by ATR-IR on human bones and teeth to assess or reject occurrence of high-temperature fires both in forensic and in archaeological bone sample remains. Even when the shape of the $v_{4}$ band is different from the expected profile, the comparison between ATR-IR and XRD data may contribute to reconstruct the firing processes to which the bones were subjected.

For example, the presence of $\beta$-TCP in human teeth as revealed by XRD may be additional evidence of a thermal treatment equivalent to at least $750^{\circ} \mathrm{C}$. Normally the $\mathrm{CI}$ values from ATR-IR spectra conducted for estimating the heat treatment are correlated just to the XRD peak sharpening from the apatite phase, throughout a line broadening analysis. On the other hand, also analysis of the $v_{4}$ band of phosphates deviating from the conventional shape so far examined can be interpreted more rigorously.

The reason why $\beta$-TCP appears at relatively moderate temperature in teeth examined here in comparison to bones still remains obscure, and further studies need to be addressed acquiring information about chemical species and following the crystal structure parameters.

\section{Conflict of Interests}

The authors declare that there is no conflict of interests regarding the publication of this paper.

\section{Acknowledgments}

The authors thank Professor Marco Zedda (Department of Animal Biology, University of Sassari, Italy) and Dr. Michele Guirguis (Department of History, University of Sassari, Italy) for supplying some osseous materials employed in this study and Professor Plinio Innocenzi, Dr. Luca Malfatti, and Dr. Barbara Lasio [Sciences and Nanotechnology Laboratory (LMNT), University of Sassari, Italy]. This work is supported by Autonomous Region of Sardinia, with the project titled "Archaeometric and Physico-Chemical Investigation Using a Multi-Technique Approach on Archaeological, Anthropological and Paleontological Materials from the Mediterranean Area and Sardinia."

\section{References}

[1] R. J. March, "L'étude des structures de combustion préhistoriques: une approche interdisciplinaire," in XIII International Congress of Prehistoric and protohistoric Sciences, O. Bar-Josef, L. Cavalli-Sforza, R. J. March, and Piperno, Eds., Colloquia 5 The Lower and Middle Paleolithic Colloquium IX, pp. 251-275, Forli, Italy, September 1996. 
[2] D. W. Owsley, "Identification of the fragmentary, burned remains of two U.S. journalists seven years after their disappearance in Guatemala," Journal of Forensic Sciences, vol. 38, no. 6, pp. 1372-1382, 1993.

[3] K. A. Murray and J. C. Rose, "The analysis of cremains: a case study involving the inappropriate disposal of mortuary remains," Journal of Forensic Sciences, vol. 38, no. 1, pp. 98-103, 1993.

[4] J. L. Holden, J. G. Clement, and P. P. Phakey, "Age and temperature related changes to the ultrastructure and composition of human bone mineral," Journal of Bone and Mineral Research, vol. 10, no. 9, pp. 1400-1409, 1995.

[5] K. A. R. Kennedy, "The wrong urn: commingling of cremains in mortuary practices," Journal of Forensic Sciences, vol. 41, no. 4, pp. 689-692, 1996.

[6] C. Cattaneo, S. DiMartino, S. Scali, O. E. Craig, M. Grandi, and R. J. Sokol, "Determining the human origin of fragments of burnt bone: a comparative study of histological, immunological and DNA techniques," Forensic Science International, vol. 102, no. 2-3, pp. 181-191, 1999.

[7] P. Shipman, G. Foster, and M. Schoeninger, "Burnt bones and teeth: an experimental study of color, morphology, crystal structure and shrinkage," Journal of Archaeological Science, vol. 11, no. 4, pp. 307-325, 1984.

[8] H. Newesely, "Chemical stability of hydroxyapatite under different conditions," in Trace Elements in Environmental History: Proceedings of the Symposium held from June 24th to 26th, 1987, at Göttingen, G. Grupe and B. Herrmann, Eds., Proceedings in Life Sciences, pp. 1-16, Springer, Berlin, Germany, 1988.

[9] M. C. Stiner, S. L. Kuhn, S. Weiner, and O. Bar-Yosef, "Differential burning, recrystallization, and fragmentation of archaeological bone," Journal of Archaeological Science, vol. 22, no. 2, pp. 223-237, 1995.

[10] A. Ravaglioli, A. Krajewski, G. C. Celotti et al., "Mineral evolution of bone," Biomaterials, vol. 17, no. 6, pp. 617-622, 1996.

[11] K. D. Rogers and P. Daniels, "An X-ray diffraction study of the effects of heat treatment on bone mineral microstructure," Biomaterials, vol. 23, no. 12, pp. 2577-2585, 2002.

[12] G. Piga, A. Malgosa, T. J. U. Thompson, and S. Enzo, "A new calibration of the XRD technique for the study of archaeological burned human remains," Journal of Archaeological Science, vol. 35, no. 8, pp. 2171-2178, 2008.

[13] G. Piga, T. J. U. Thompson, A. Malgosa, and S. Enzo, "The potential of X-ray diffraction in the analysis of burned remains from forensic contexts," Journal of Forensic Sciences, vol. 54, no. 3, pp. 534-539, 2009.

[14] G. Piga, The use of spectroscopy and diffraction techniques in the study of bones and implications in anthropology, paleontology and forensic sciences [Ph.D. thesis], Biblioteca de Comunicación y Hemeroteca General, Universitat Autónoma de Barcelona, 2012, http://www.educacion.es/teseo/mostrarRef .do?ref=996840.

[15] H. E. C. Koon, R. A. Nicholson, and M. J. Collins, "A practical approach to the identification of low temperature heated bone using TEM," Journal of Archaeological Science, vol. 30, no. 11, pp. 1393-1399, 2003.

[16] L. E. Munro, F. J. Longstaffe, and C. D. White, "Burning and boiling of modern deer bone: effects on crystallinity and oxygen isotope composition of bioapatite phosphate," Palaeogeography, Palaeoclimatology, Palaeoecology, vol. 249, no. 1-2, pp. 90-102, 2007.
[17] J. Olsen, J. Heinemeier, P. Bennike, C. Krause, K. Margrethe Hornstrup, and H. Thrane, "Characterisation and blind testing of radiocarbon dating of cremated bone," Journal of Archaeological Science, vol. 35, no. 3, pp. 791-800, 2008.

[18] T. J. U. Thompson, M. Gauthier, and M. Islam, “The application of a new method of Fourier Transform Infrared Spectroscopy to the analysis of burned bone," Journal of Archaeological Science, vol. 36, no. 3, pp. 910-914, 2009.

[19] T. J. U. Thompson, M. Islam, K. Piduru, and A. Marcel, "An investigation into the internal and external variables acting on crystallinity index using Fourier Transform Infrared Spectroscopy on unaltered and burned bone," Palaeogeography, Palaeoclimatology, Palaeoecology, vol. 299, no. 1-2, pp. 168-174, 2011.

[20] G. Piga, M. Guirguis, P. Bartoloni, A. Malgosa, and S. Enzo, "A funerary rite study of the Phoenician-Punic necropolis of Mount Sirai (Sardinia, Italy)," International Journal of Osteoarchaeology, vol. 20, no. 2, pp. 144-157, 2010.

[21] G. Piga, A. Malgosa, T. J. U. Thompson, M. Guirguis, and S. Enzo, "A unique case of prone position in the primary cremation Tomb 252 of Monte Sirai necropolis (Carbonia, Sardinia, Italy)," International Journal of Osteoarchaeology, vol. 25, no. 2, pp. 146159, 2015.

[22] K. E. Squires, T. J. U. Thompson, M. Islam, and A. Chamberlain, "The application of histomorphometry and Fourier Transform Infrared Spectroscopy to the analysis of early Anglo-Saxon burned bone," Journal of Archaeological Science, vol. 38, no. 9, pp. 2399-2409, 2011.

[23] G. Piga, J. H. Hernández-Gasch, A. Malgosa, M. L. Ganadu, and S. Enzo, "Cremation practices coexisting at the S'Illot des Porros Necropolis during the Second Iron Age in the Balearic Islands (Spain)," HOMO-Journal of Comparative Human Biology, vol. 61, no. 6, pp. 440-452, 2010.

[24] S. Chakraborty, S. Bag, S. Pal, and A. K. Mukherjee, "Structural and microstructural characterization of bioapatites and synthetic hydroxyapatite using X-ray powder diffraction and Fourier transform infrared techniques," Journal of Applied Crystallography, vol. 39, no. 3, pp. 385-390, 2006.

[25] G. Piga, A. Brunetti, B. Lasio, S. Enzo, and A. Malgosa, "XRF investigation on skeletal remains from King Peter III of Aragon (1239-1285 A.D) and Queen Blanche of Anjou (1280-1310 A.D)," Applied Physics A, vol. 114, no. 3, pp. 647-653, 2014.

[26] S. Weiner, P. Goldberg, and O. Bar-Yosef, "Bone preservation in Kebara Cave, Israel using on-site Fourier transform infrared spectrometry," Journal of Archaeological Science, vol. 20, no. 6, pp. 613-627, 1993.

[27] L. E. Wright and H. P. Schwarcz, "Infrared and isotopic evidence for diagenesis of bone apatite at Dos Pilas, Guatemala: palaeodietary implications," Journal of Archaeological Science, vol. 23, no. 6, pp. 939-944, 1996.

[28] G. Piga, G. Solinas, T. J. U. Thompson, A. Brunetti, A. Malgosa, and S. Enzo, "Is X-ray diffraction able to distinguish between animal and human bones?" Journal of Archaeological Science, vol. 40, no. 1, pp. 778-785, 2013.

[29] T. J. U. Thompson, M. Islam, and M. Bonniere, "A new statistical approach for determining the crystallinity of heat-altered bone mineral from FTIR spectra," Journal of Archaeological Science, vol. 40, no. 1, pp. 416-422, 2013.

[30] S. Weiner and O. Bar-Yosef, "States of preservation of bones from prehistoric sites in the Near East: a survey," Journal of Archaeological Science, vol. 17, no. 2, pp. 187-196, 1990. 
[31] H. M. Rietveld, "Line profiles of neutron powder-diffraction peaks for structure refinement," Acta Crystallographica, vol. 22, no. 1, pp. 151-152, 1967.

[32] L. Lutterotti, “Total pattern fitting for the combined size-strainstress-texture determination in thin film diffraction," Nuclear Instruments and Methods in Physics Research, Section B: Beam Interactions with Materials and Atoms, vol. 268, no. 3-4, pp. 334340,2010

[33] S. Graulis, D. Chateigner, R. T. Downs et al., "Crystallography Open Database-an open-access collection of crystal structures," Journal of Applied Crystallography, vol. 42, no. 4, pp. 726$729,2009$.

[34] M. Lebon, I. Reiche, F. Fröhlich, J.-J. Bahain, and C. Falguères, "Characterization of archaeological burnt bones: contribution of a new analytical protocol based on derivative FTIR spectroscopy and curve fitting of the $v_{1} v_{3} \mathrm{PO}_{4}$ domain," Analytical and Bioanalytical Chemistry, vol. 392, no. 7, pp. 1479-1488, 2008.

[35] H. L. Jang, H. K. Lee, K. Jin, H.-Y. Ahn, H.-E. Lee, and K. T. Nam, "Phase transformation from hydroxyapatite to the secondary bone mineral, whitlockite," Journal of Materials Chemistry B, vol. 3, no. 7, pp. 1342-1349, 2015.

[36] J. C. Elliott, Structure and Chemistry of the Apatites and Other Calcium Orthophosphates, Elsevier Science \& Technology, Amsterdam, The Netherlands, 1994.

[37] T. Sui, M. A. Sandholzer, A. J. G. Lunt et al., "In situ X-ray scattering evaluation of heatinduced ultrastructural changes in dental tissues and synthetic hydroxyapatite," Journal of the Royal Society Interface, vol. 11, no. 95, Article ID 20130928, 2014.

[38] R. M. Wilson, J. C. Elliott, and S. E. P. Dowker, "Rietveld refinement of the crystallographic structure of human dental enamel apatites," American Mineralogist, vol. 84, no. 9, pp. 14061414, 1999.

[39] M. Yashima, A. Sakai, T. Kamiyama, and A. Hoshikawa, "Crystal structure analysis of $\beta$-tricalcium phosphate $\mathrm{Ca}_{3}\left(\mathrm{PO}_{4}\right)_{2}$ by neutron powder diffraction," Journal of Solid State Chemistry, vol. 175, no. 2, pp. 272-277, 2003. 

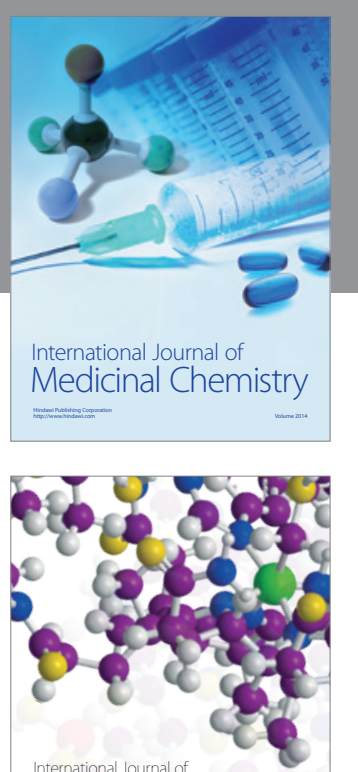

Carbohydrate Chemistry

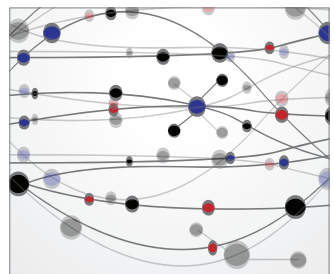

The Scientific World Journal
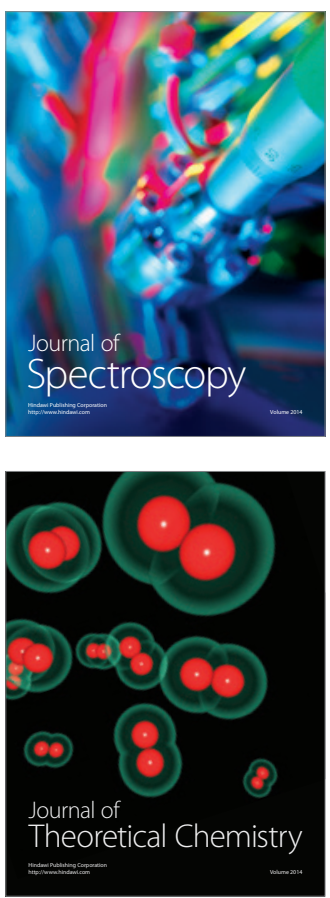
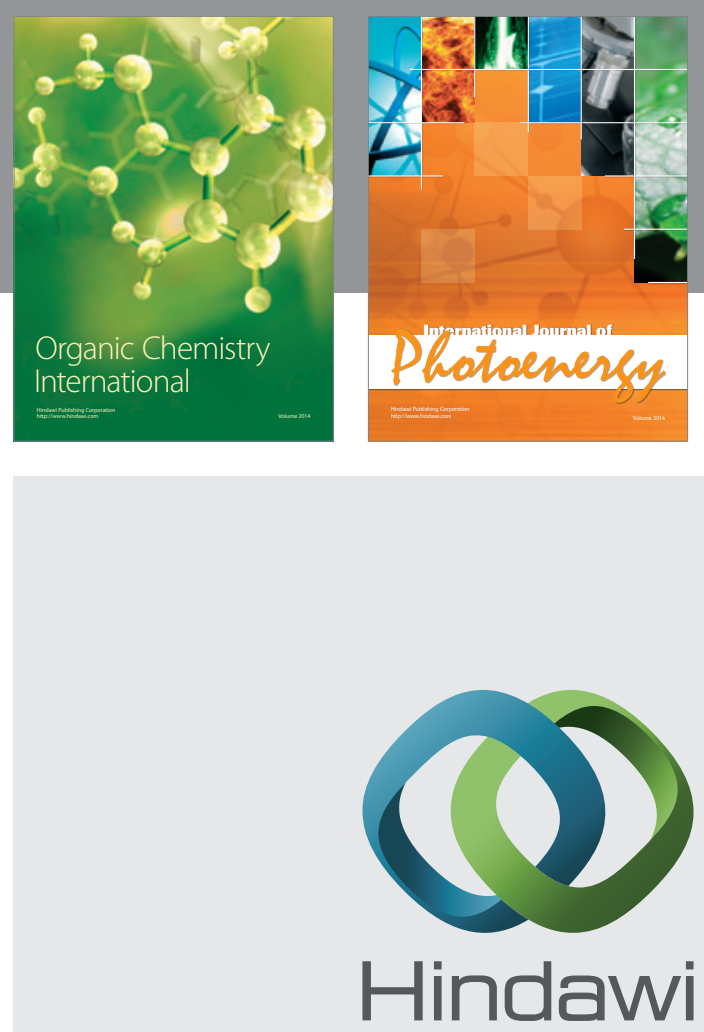

Submit your manuscripts at

http://www.hindawi.com

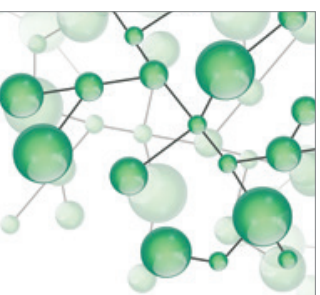

International Journal of

Inorganic Chemistry

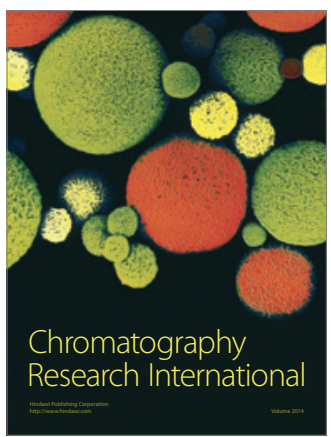

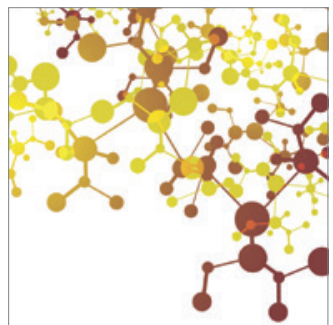

Applied Chemistry
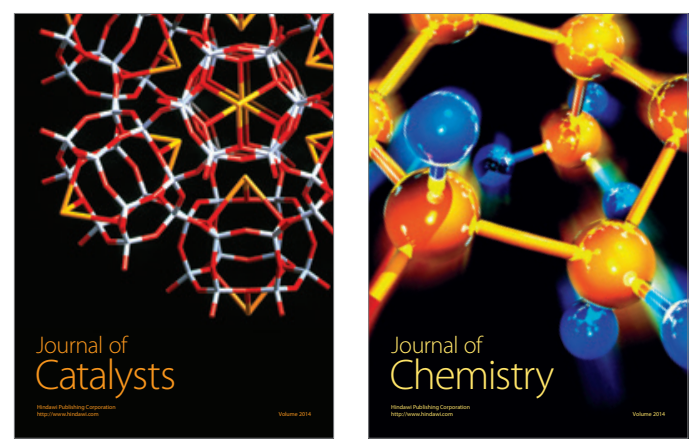
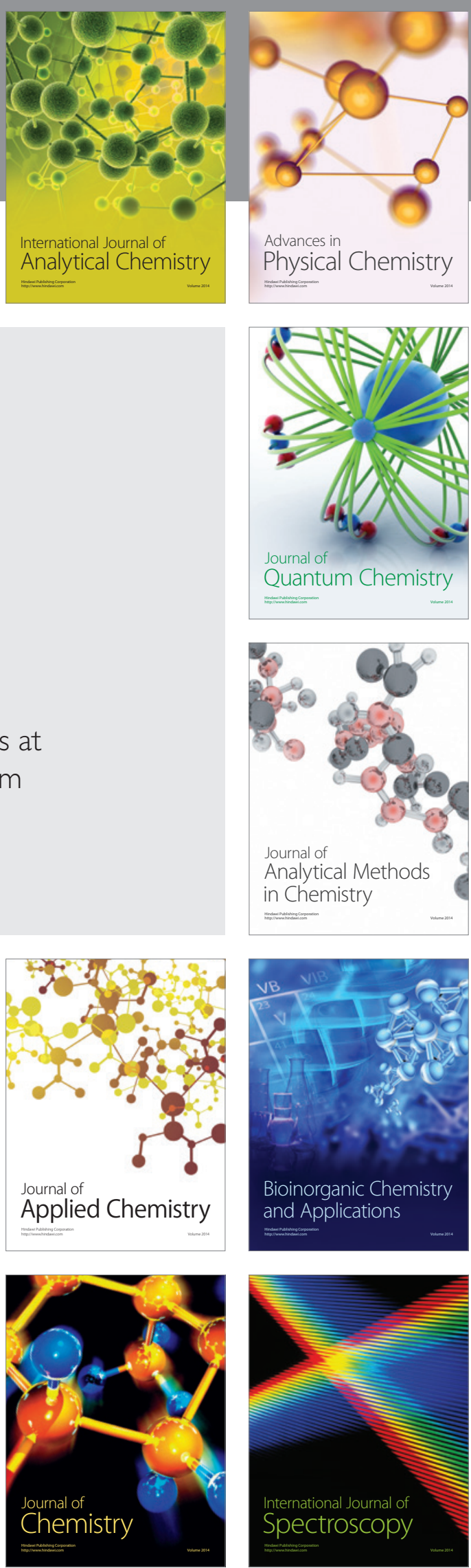